\title{
Study of Si-Implanted and Thermally Annealed Layers of Silicon by Using X-ray Grazing Incidence Methods
}

\author{
D. KlingeR ${ }^{a} *$, M. Lefeld-SosnowskA ${ }^{b}$, J.B. PeŁKA ${ }^{a}$, \\ W. Paszkowicz ${ }^{a}$, P. Gier Powski $^{a}$ AND P. PAnkowski ${ }^{a}$ \\ ${ }^{a}$ Institute of Physics, Polish Academy of Sciences \\ al. Lotników 32/46, 02-668 Warsaw, Poland \\ ${ }^{b}$ Institute of Experimental Physics, Warsaw University \\ Hoża 69, 00-681 Warsaw, Poland
}

\begin{abstract}
This paper reports on the study of structural modifications induced by the implantation process and by the subsequent thermal annealing in near-surface layers of $\mathrm{Si}$ single crystals implanted with $\mathrm{Si}^{2+}$ ions of energy $140 \mathrm{keV}$ and doses from $1 \times 10^{15}$ to $1 \times 10^{16}$ ions $/ \mathrm{cm}^{2}$. The grazing incidence $\mathrm{X}$-ray diffraction and X-ray reflectivity measurements were applied to determine the thickness and structural composition of the damaged layers. The fitted electron density profiles indicated an existence of an interfacial layer with density higher than the density of Si matrix or near-surface oxide layer. Formation of polycrystalline phases of silicon and silicon oxides is discussed in dependence on the conditions of annealing treatment and implantation dose.
\end{abstract}

PACS numbers: 61.10.-i, 61.10.Kw, 61.72.Tt, 68.35.Fx, 81.40.Ef, 81.65.Mq

\section{Introduction}

The surface oxidation of crystalline semiconductors is one of the most physically fundamental and technologically ubiquitous of solid-state processes. Many studies concerned the oxides epitaxially growing on $\mathrm{Si}$ surfaces and especially the silicon/silicon oxide interface $[1,2]$. The studies of this interfacial region have reported a high-density layer abounding with $\mathrm{Si}$ compared to $\mathrm{SiO}_{2}$ [3].

*corresponding author; e-mail: kling@ifpan.edu.pl 
Implantation process for silicon crystals leads to creation of the structural changes in the near-surface layer, it can lead to formation of the secondary phase. In most of cases the oxide precipitates in the top silicon layer were observed [4-6]. The thin layers of the silicon oxide were grown at room temperature on the $\mathrm{Si}$ substrates after low-energy copper implantation [7] or high-energy implantation with oxygen ions $[8,9]$.

In this paper we report on the studies of structural modifications induced by the implantation process with $\mathrm{Si}^{2+}$ ions at the room temperature and by the subsequent thermal annealing in thin near-surface layer of Si single crystal.

\section{Experimental}

Silicon samples cut perpendicularly to the $\langle 111\rangle$ axis were implanted with $140 \mathrm{keV} \mathrm{Si}{ }^{2+}$ ions at doses of $1 \times 10^{15}$ or $1 \times 10^{16} \mathrm{~cm}^{-2}$. Samples were annealed at $900^{\circ} \mathrm{C}$ for $46 \mathrm{~h}$. Particular care was taken to minimize a possible contribution from ${ }^{14} N^{+}$ions.

Grazing-incidence X-ray reflectivity (GIXR) patterns were recorded at W1.1 wiggler beam line at Hasylab (Hamburg). The monochromator was set to $10.000 \mathrm{keV}(\lambda=1.2398 \AA)$. The incident beam width was limited to $40 \mu \mathrm{m}$ by means of slits, the value small enough to keep the whole spot within the sample surface from below the critical angle of incidence. The FWHM of the reflectometer was estimated to be of $0.0025 \pm 0.0005^{\circ}$.

The X-ray diffraction patterns were measured by a powder diffractometer installed at the B2 beam line at Hasylab (Hamburg), using a parallel beam monochromatized with a Ge(111) double crystal monochromator. The diffractometer was equipped with a set of parallel horizontal foils (of angular aperture $0.1^{\circ}$ ) at the diffracted beam. The patterns reported in this work were recorded with monochromator set to $\lambda=1.1368 \AA$. The wavelength was determined by a least squares procedure for silicon NBS $640 \mathrm{~b}$ standard $\left(a_{\mathrm{Si}}=5.43094 \AA\right)$. The incident beam geometry with grazing angle fixed at $0.7^{\circ}$ was employed during the measurements.

\section{Results}

Table I contains the data of the representative samples A, B, and C, for which we obtained clear differences between structural modifications induced by implantation process and thermal annealing in the near-surface layer and for which the results of measurements by using $\mathrm{X}$-ray grazing incidence methods are shown below.

Figure 1 shows the diffraction patterns obtained for the investigated samples. The typical pattern received for the non-implanted over side of sample A is presented in Fig. 1a. As it can be observed, there are no clear traces of a crystalline $\mathrm{SiO}_{x}$ phase. 
TABLE I

Samples measured by using X-ray grazing incidence methods.

\begin{tabular}{c|c|c}
\hline \hline Sample of Si crystal & Implantation process & Thermal annealing \\
\hline sample A & $140 \mathrm{keV} \mathrm{Si}^{2+}$ ions at a dose $1 \times 10^{15} \mathrm{~cm}^{-2}$ & - \\
sample B & $140 \mathrm{keV} \mathrm{Si}^{2+}$ ions at a dose $1 \times 10^{15} \mathrm{~cm}^{-2}$ & $900^{\circ}, 46 \mathrm{~h}$ \\
sample C & $140 \mathrm{keV} \mathrm{Si}{ }^{2+}$ ions at a dose $1 \times 10^{16} \mathrm{~cm}^{-2}$ & $900^{\circ}, 46 \mathrm{~h}$
\end{tabular}

The diffraction pattern obtained for the implanted side of sample A is shown in Fig. 1b. Besides the broad band at $18-22^{\circ}(2 \theta)$ we observe the distinct diffraction peaks at angles $\approx 28^{\circ}, \approx 33^{\circ}$ and $\approx 47^{\circ}$. The run of the diffraction curve, position and intensity relation of these peaks indicate the presence of polycrystalline $\mathrm{SiO}_{x}$ phases mixed with amorphous phase in the near-surface layer.

Figures $1 c$ and d show the diffraction patterns obtained for samples B and C (implanted and annealed, see Table I). As a consequence of the thermal annealing, in both cases, the amorphous phase almost completely disappears. On the other
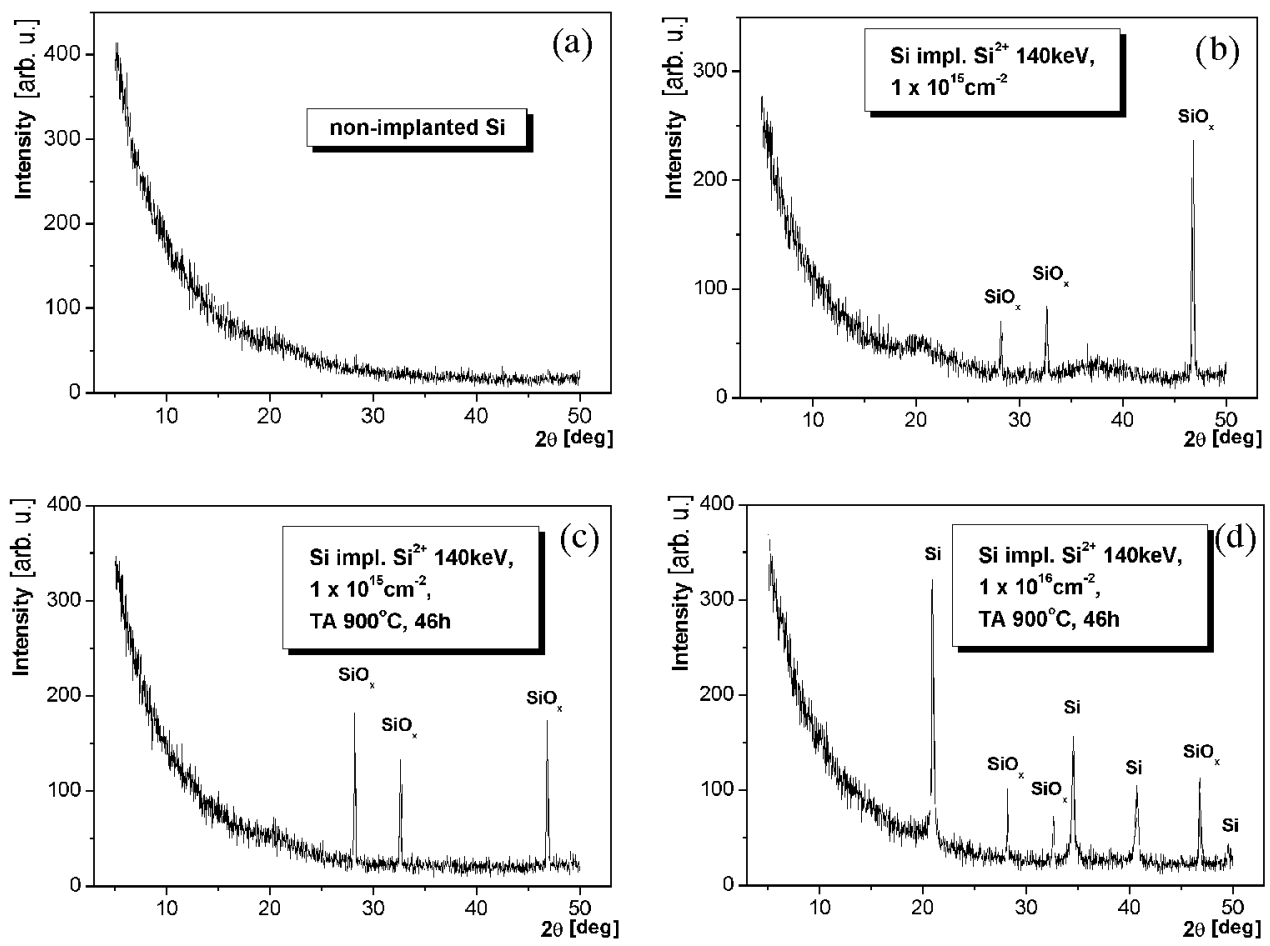

Fig. 1. Diffraction patterns obtained for selected samples: (a) non-implanted over side of non-annealed sample, (b) Si sample implanted with $140 \mathrm{keV} \mathrm{Si}^{2+}$ ions at a dose $1 \times 10^{15} \mathrm{~cm}^{-2}$, (c)-(d) Si samples implanted with $\mathrm{Si}^{2+}$ ions at doses $1 \times 10^{15} \mathrm{~cm}^{-2}$ and $1 \times 10^{16} \mathrm{~cm}^{-2}$, respectively, and then thermally annealed. 
hand, we observe the distinct diffraction peaks at angles $\approx 28^{\circ}, \approx 33^{\circ}$ and $\approx 47^{\circ}$ like for the non-annealed sample $A$. These changes of intensity relation in diffraction patterns confirm some ordering of the polycrystalline $\mathrm{SiO}_{x}$ phase induced by thermal annealing. In the diffraction pattern obtained for sample $\mathrm{C}$ we observe the appearance of new peaks. Their positions and intensity relation point to the presence of the polycrystalline silicon.

Figure 2 shows the experimental reflectivity with the corresponding fits. To fit the data we used a computer model electron density profiles with parameters that represent the bulk substrate, the oxide overlayer and the interfacial layer. These last two layers can consist of several layers and each of them is described by density $\rho_{i}$ and layer thickness $d_{i}$. A computer algorithm was based on the Parratt iterative procedure making use of the Fresnel formula [10].

The experimental reflectivity measured for sample A (implanted and non-annealed, see Table I) with the best fitting result is shown in Fig. 2a. The theoretical parameters used to fit are presented in Table II. The run of the ex-
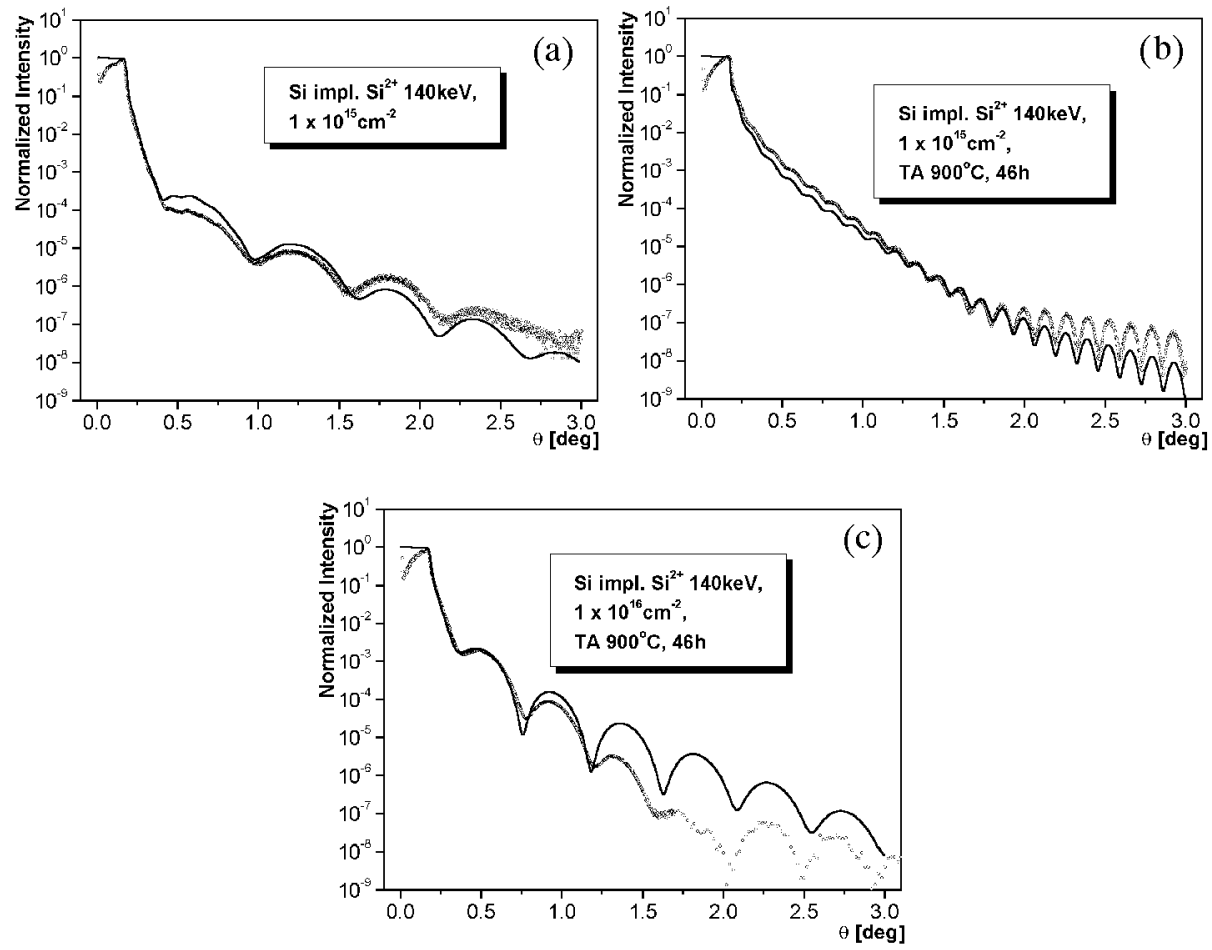

Fig. 2. Experimental reflectivity profiles with the corresponding fits (solid line): (a)-(b) Si sample implanted of $\mathrm{Si}^{2+}$ ions at a dose $1 \times 10^{15} \mathrm{~cm}^{-2}$, non-annealed or thermally annealed, respectively, (c) Si sample implanted with $\mathrm{Si}^{2+}$ ions at a dose $1 \times 10^{16} \mathrm{~cm}^{-2}$ and thermally annealed. 
perimental reflectivity shows that owing to implantation process, the near-surface layer with electron density clearly different from the electron density of the bulk material was created. The experimental reflectivity shows the oscillations with a period being a function of the near-surface layer thickness. The fitted parameters suggest that close to the surface a thin silicon oxide film of low mass density was formed (thickness $d=d_{1}+d_{2}=59 \AA$ ). At the silicon/silicon oxide interface a high-density layer with a theoretical thickness (thickness $d=d_{3}+d_{4}=188 \AA$ ) was created. This result is in agreement with the results of theoretical studies of the crystalline Si oxidation and especially of the silicon/silicon oxide interface [3].

\section{TABLE II}

Modeled structure of the samples A (Si implanted with $\mathrm{Si}^{2+}$ ions at a dose $1 \times 10^{15} \mathrm{~cm}^{-2}$ ).

\begin{tabular}{c|c|c|c|c}
\hline \hline & Material & $\begin{array}{c}\text { Density, } \rho \\
{\left[\mathrm{g} / \mathrm{cm}^{2}\right]}\end{array}$ & $\begin{array}{c}\text { Thickness, } d \\
{[\AA]}\end{array}$ & $\begin{array}{c}\text { Roughness, } \rho \\
{[\AA]}\end{array}$ \\
\hline top oxide layer & $\mathrm{SiO}_{2}$ & 1.4 & 27.00 & 3.70 \\
& $\mathrm{SiO}$ & 1.67 & 32.00 & 4.30 \\
interface layer & $\mathrm{SiO}$ & 2.8 & 8.00 & 8.50 \\
& $\mathrm{SiO}$ & 2.29 & 180.00 & 3.80 \\
bulk substrate & $\mathrm{Si}$ & 2.33 & & 8.00
\end{tabular}

In Fig. 2b we present the experimental reflectivity obtained for sample B (implanted and annealed) with the best theoretical reflectivity. The fitted parameters for this sample were comprised in Table III. The near-surface layers with electron density different from density of the bulk material were formed as a consequence of implantation process and thermal annealing. The thickness of the near-surface oxide layer was higher than in the case of non-annealed sample and it equals $d=12 \AA$. At a very sharp interface the thick silicon layer $(d=255 \AA)$ of the density slightly lower than the density of the substrate was formed.

TABLE III

Modeled structure of the samples $\mathrm{B}$ ( $\mathrm{Si}$ implanted with $\mathrm{Si}^{2+}$ ions at a dose $1 \times 10^{15} \mathrm{~cm}^{-2}$, thermally annealed).

\begin{tabular}{l|c|c|c|c}
\hline \hline & Material & $\begin{array}{c}\text { Density, } d \\
{\left[\mathrm{~g} / \mathrm{cm}^{2}\right]}\end{array}$ & $\begin{array}{c}\text { Thickness, } d \\
{[\AA]}\end{array}$ & $\begin{array}{c}\text { Roughness, } \rho \\
{[\AA]}\end{array}$ \\
\hline top oxide layer & $\mathrm{SiO}_{2}$ & 2.1 & 12.00 & 5.30 \\
interface layer & $\mathrm{Si}$ & 2.2 & 255.00 & \\
bulk substrate & $\mathrm{Si}$ & 2.33 & & 8.00
\end{tabular}


TABLE IV

Modeled structure of the samples $\mathrm{C}$ ( $\mathrm{Si}$ implanted with $\mathrm{Si}^{2+}$ ions at a dose $1 \times 10^{16} \mathrm{~cm}^{-2}$, thermally annealed).

\begin{tabular}{l|c|c|c|c}
\hline \hline & Material & $\begin{array}{c}\text { Density, } \rho \\
{\left[\mathrm{g} / \mathrm{cm}^{2}\right]}\end{array}$ & $\begin{array}{c}\text { Thickness, } d \\
{[\AA]}\end{array}$ & $\begin{array}{c}\text { Roughness, } \rho \\
{[\AA]}\end{array}$ \\
\hline top oxide layer & $\mathrm{SiO}$ & 2.2 & 42.00 & 3.5 \\
& $\mathrm{SiO}$ & 2.1 & 35.00 & 6.00 \\
interface layer & $\mathrm{SiO}$ & 3.6 & 10.00 & 4.00 \\
bulk substrate & $\mathrm{Si}$ & 2.33 & & 8.00
\end{tabular}

The experimental and theoretical reflectivity obtained for sample C (implanted and annealed, see Table I) are shown in Fig. 2c. The fitted parameters for this sample are given in Table IV. Similarly for the last sample, the near-surface layer ( $d=d_{1}+d_{2}=77 \AA$ ) with the electron density different from the bulk material electron density was formed as a consequence of implantation process and thermal annealing. In the fit model we assumed the existence of a very thin $(d=12 \AA)$, highly-dense $\left(\rho=3.6 \mathrm{~g} / \mathrm{cm}^{2}\right)$ oxide layer covered with a near-surface oxide layer at the silicon/silicon oxide interface.

\section{Summary}

We have studied structural modifications induced in thin near-surface layer of an $\mathrm{Si}$ single crystal by the implantation process of $\mathrm{Si}^{2+}$ ions and by the subsequent thermal annealing. The grazing-incidence X-ray diffraction and X-ray reflectivity measurements were applied to determine the thickness and structural composition of the damaged layers. The fitted electron density profiles indicated an existence of an interfacial layer with density higher than the density of Si matrix or near-surface oxide layer. Annealing process decreased the thickness of this interfacial layer. This finding is comparable with the results of theoretical studies of the crystalline Si oxidation and specially of the silicon/silicon oxide interface [3].

As a consequence of implantation process, the near-surface layer of the amorphous phase mixed with polycrystalline $\mathrm{SiO}_{x}$ phases was formed. As expected, the amorphous phase almost completely disappeared owing to thermal annealing, while some ordering in the $\mathrm{SiO}_{x}$ phase was induced. Additionally the polycrystalline phase of Si appeared in the near-surface layer of Si sample implanted with ions at higher dose and thermally annealed.

\section{Acknowledgments}

This work was supported by the State Committee for Scientific Research, grant no. 2P 03B 095 16. Synchrotron measurements were done at HASYLAB, 
Hamburg and were supported by the IHP-Contract HPRI-CT-1999-00040 of the European Community.

\section{References}

[1] T.A. Rabadeau, I.M. Tidswell, P.S. Pershan, J. Bevk, B.S. Freer, Appl. Phys. Lett. 59, 706 (1991).

[2] T.A. Rabadeau, I.M. Tidswell, P.S. Pershan, J. Bevk, B.S. Freer, Appl. Phys. Lett. 59, 422 (1991).

[3] S.D. Kosovsky, P.S. Pershan, K.S. Krish, J. Bevk, M.L. Green, D. Brasen, L.C. Feldman, P.K. Roy, Appl. Phys. Lett. 70, 3119 (1997).

[4] Handbook of Ion Implantation Technology, Ed. J.F. Ziegler, IBM-Research Yorktown Heights, New York 1992, p. 203.

[5] O.W. Holland, D.S. Zhou, D.K. Thomas, Appl. Phys. Lett. 63, 896 (1993).

[6] H.L. Meng, S. Prussin, M.E. Law, K.S. Jones, J. Appl. Phys. 73, 955 (1993).

[7] E.J. Jaquez, T.L. Alford, N.D. Theodore, D. Adams, Li Jian, S.W. Russell, S. Anders, in: Thermodynamics and Kinetics of Phase Transformations, Symposium, Eds. J.S. Im, B. Park, A.L. Greer, G.B. Stephenson, Mater. Res. Soc., Pittsburgh, PA 1996, p. 189.

[8] S. Ellingboe, M.C. Ridgway, P.J. Schultz, J. Appl. Phys. 73, 1133 (1993).

[9] Xianfang Zhu, J.S. Williams, J.C. McCallum, Nucl. Instrum. Methods Phys. Res. $B$ 148, 268 (1999).

[10] L.G. Parratt, Phys. Rev. 59, 359 (1954). 